FAMOUS FIGURES

\title{
Shrapnel: The Man, The Missile And The Myth
}

D G Burris MD FACS

DMCC (COL MC

USA)

Interim Chairman

Department of Surgery,

USUHS,

4301 Jones Bridge

Road,

Bethesda, MD 20814-

4799,

USA.

N M Rich MD FACS

DMCC (COL MC

USA RET)

Norman M Rich

Department of Surgery,

F.Edward Hébert

School of Medicine,

Uniformed Services

University of the Health

Sciences,

Bethesda, MD, USA.

J M Ryan MCh FRCS

DMCC (Col, L/RAMC)

The Leonard Cheshire

Centre for Conflict

Recovery,

University College,

London.

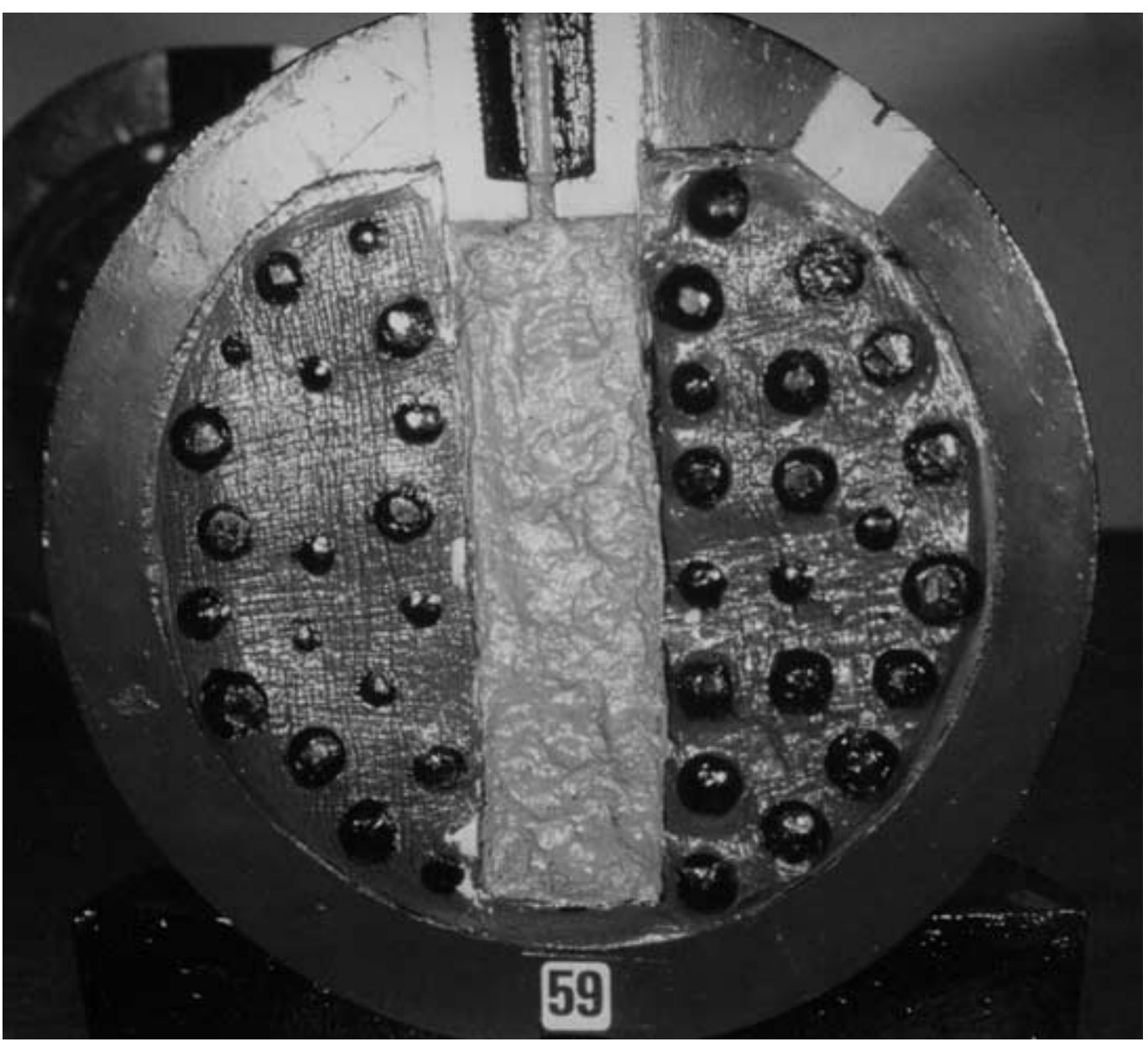

Fig 1. Mid nineteenth century shrapnel ball.

"...Great numbers of shell splinters usually described most erroneously as Shrapnel will be falling in the streets." Winston S. Churchill, 1940 (1).

By the time of his appointment as the First Lord of the Admiralty, Winston Churchill had served in military action in Cuba, India and South Africa during the end of the 19th Century. Prior to WW1, his unceasing study of armaments and force of will contributed to the development of a modernised British Navy that was instrumental in the defeat of Germany in that war. He asked for, and received a position as a Lieutenant Colonel commanding the 6th Royal Scots Fusiliers and commanded troops in the trenches, where he experienced shelling by a variety of munitions. This war saw the end of the old styles of weapons of the previous century, and the dawn of modern explosive munitions. These experiences, and his study, lead to his insistence on accuracy during a speech as Prime Minister in WW11, as excerpted above.

The Oxford English Dictionary Online gives the primary definition of Shrapnel as:

"A hollow projectile containing bullets and a small bursting charge, which when fired by the time fuse, bursts the shell and scatters the bullets in a shower" (2).

Many Physicians and Surgeons appreciate and enjoy knowing more of their heritage. Yet few are aware that the commonly used and misused term of "Shrapnel" was actually derived from the name of a Military Officer, who later rose to the rank of Major General in the British Army, who invented it nearly 200 years ago. Nor is it recognised that the Shrapnel shell had essentially disappeared by the early part of WW 1 being replaced by the high explosive artillery shell.

While the third definition in the Oxford Dictionary allows that this term is used to denote "fragments from shells or bombs", it is accompanied by references from the 


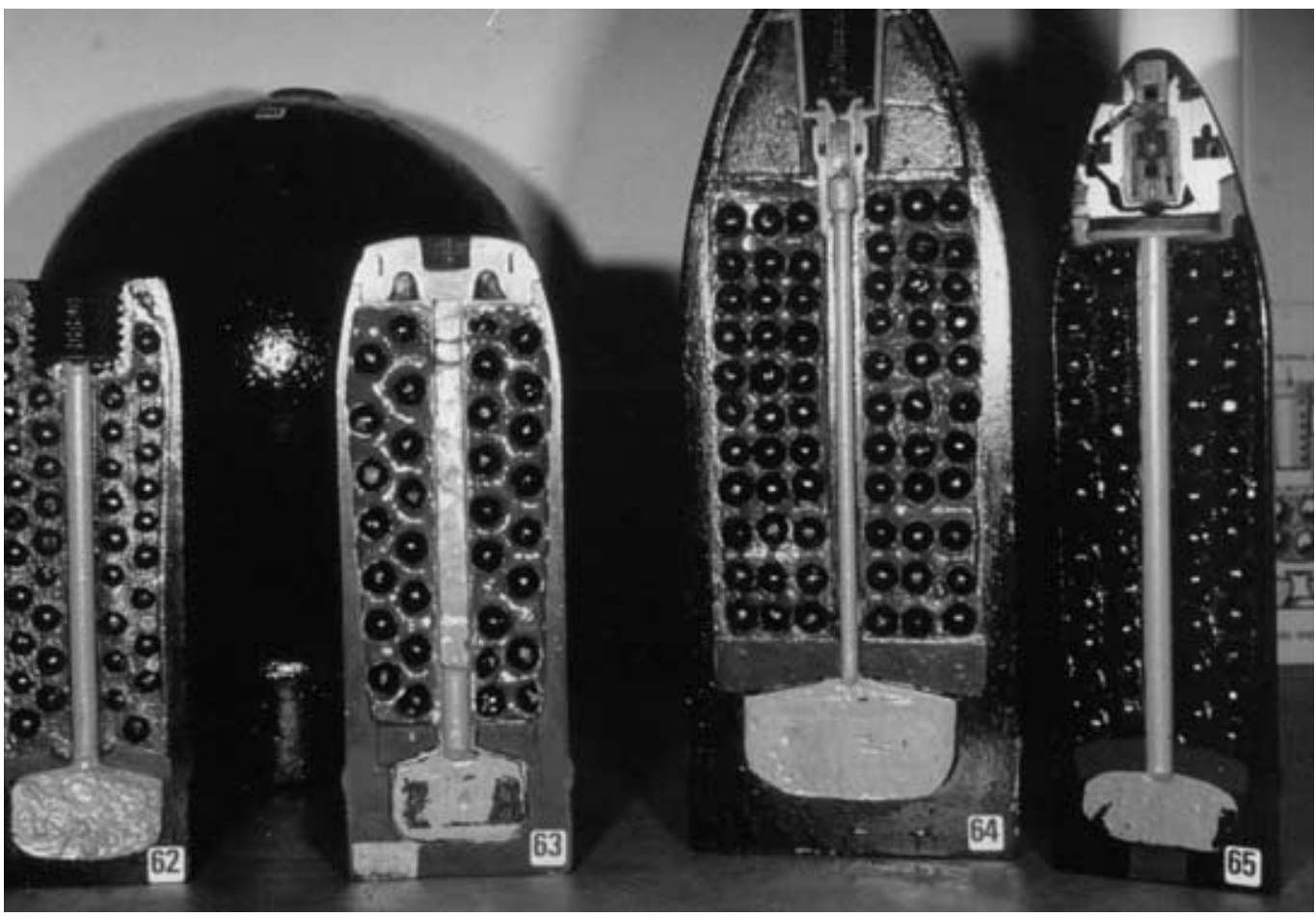

Fig 2. Shrapnel shells from the First World War.

1940s that discourage this. This effort was continued by one of the authors (NMR) in a short historical note and an editorial $(3,4)$ both approximately 35 years ago, making a plea that the term "fragment" would be more appropriate than "Shrapnel" in describing wounds caused by a variety of devices that sent multiple fragments through the air. While definitions were addressed it remains popular, unfortunately, around the world to describe multiple wounds as Shrapnel wounds. Recognising that wars and increasing terrorist acts continue to plague civilian populations, as well as military organisations in many parts of the world, it seems timely to readdress the question and review historical information.

With the availability of the World Wide Web it is interesting to identify the many citations associated with Shrapnel. These range from Shrapnel games (5) to Shrapnel bands (flying metal) (6), Shrapnel publications, Shrapnel entertainers and the list goes on. A variety of citations would seem to suggest that 19th Century artillery was responsible for the downing of TWA flight 800 (7), and for the wounds sustained by an Afghani farmer (8). There is one pertinent citation "What is the difference between artillery shell and shell fragments?" (9) that appears under Shrapnel vs. Shell Fragments which is stated to be an edited version of Major General HW Blakely's classic article, "Shrapnel, Semantics, and Such" reprinted from the March 1952 Combat Forces fournal. This is an excellent reference and available to the non-medical community as well as to the medical community. Figure 1 is a good depiction of the Shrapnel shell and Figure 2 demonstrates the Shrapnel balls embedded in the First World War shells.

\section{Major General Henry Shrapnel}

The early canon, firing one large nonexplosive projectile, was most effective against single large targets such as battlements and ships. To increase the effectiveness against large bodies of attackers, a wide variety of multiple projectiles, including chains, rocks, nails and finally, round metal balls, known as grape shot, were utilised. These were limited in that they were most effective over short distances in a straight line from the muzzle of the weapon. In 1804 during the Battle of Suranam, the then Lieutenant, Henry Shrapnel devised an artillery shell that contained lead balls. The shell could be launched over the battlefield, and above battlements, so that with explosion of the shell the lead balls, travelling at relatively low velocity, would be hurled down onto the enemy. Shrapnel shells were used by many armies around the world for over 100 years. However, the development of the high explosive artillery shell that sent fragments of the outer casing at a higher velocity through the air was determined by 1915 , in the early part of WW1, to be much more effective than the Shrapnel shell, with the latter rapidly falling into disuse.

There was a documented accident in the United States where it was demonstrated that the effectiveness of the old Shrapnel shell was minimal in comparison to the newer high explosive artillery shells. In illustration of the ineffectiveness of the Shrapnel Shell, one of the authors (NMR) 
had a patient at Walter Reed in the late 1960s, who was a retired Brigadier General Artillery Officer, who claimed to have been in the "Last great Shrapnel barrage" in World War 1. The General emphasised that they realised the ineffectiveness of the Shrapnel shell, compared and contrasted to the new high explosive artillery shells, when the lead balls from the exploding Shrapnel shells "raining from the sky" only bruised their shoulders and made a banging noise when bouncing off their helmets.

Also, it should be noted that the development of a variety of mortars to be added to a range of artillery shells and grenades, both hand grenades and propelled grenades, sent many fragments through the air upon exploding, differing from the original Shrapnel shell. It is ironic that there has been persisting use by many of the term "Shrapnel" when "fragment" is more accurate in describing the origin of the missile and the resultant wound. Thus, Shrapnel is pre-shaped round metal balls rained down from a specially designed explosive shell, while fragments are the bits and pieces of the walls of an exploding artillery shell.
In medicine, we strive for accuracy. In striving for the accuracy asked for by Winston Churchill it would seem very appropriate to remember Henry Shrapnel, the man, and his invention of nearly 200 years ago, while avoiding the myth that multiple fragment wounds, from more modern explosive devices, are even remotely related to the original Shrapnel shell.

\section{References}

1. Churchill WS. Secret Session Speeches. Simon \& Schuster, New York 1946.

2. http://dictionary.oed.com/entrance.dtl

3. Rich NM. Shrapnel - A Misnomer. Milt Med 1967; 132(6): 470-471.

4. Rich NM. Shrapnel Wounds Letters to the Journal. fAMA 1967; 202(3): 173 .

5. http://shrapnelgames.com

6. http://www2.shrapnelrecords.com

7. Irvine R, Kincaid c. Revealed - Shrapnel Was Found In 89 TWA 800 Victims http://www.rense.com/general/shrap.htm, June 12, 2002.

8. McCarthy R. Afghan farmer 'hit by shrapnel'. Guardian Unlimited. http://www.guardian.co.uk/afghanistant/story. October 10, 2001.

9. Author unknown - Anonymous. What is the difference between artillery shrapnel and shell fragments? http://www.army.mil/cmh-pg/faq/ shrapnel.htm 